\title{
CARDIAC ARREST: A REPORT ON TEN CASES*
}

\author{
C. D. Elton, M.R.C.\$., L.R.C.F., D.A.
}

THIS IS a presentation of some cases of cardiac arrest which recovered from the event. It is hoped that these will be of interest and possibly of some use in helping to forcast the outcome of some of the more serious cases. Ten cases are offered, all of which recovered to the extent that they would appear to be able to live a normal life in the future.

The first case illustrates how even in frankly adverse conditions a good result can be obtained.

\section{Case 1: Attempted Bronchogram under Local A naesthesia}

This procedure was being performed on an 18-year-old woman in the X-ray Department by a surgeon using topical hex : lcaine as the anaesthetic agent. A small but unknown amount of this agent had just been sprayed into the trachea when the patient started to convulse. The surgeon immediately sent for an anaesthetist and by the time one arrived the patient was black with cyanosis. Some further delay was occasioned in getting the anaesthetic machine going.

It proved impossible to ventilate the patient using the bag and mask because of pharyngeal obstruction from grossly enlarged tonsils. Thiopentone (50 mg. i.v.) was given, in order to control the convulsions, and an attempt was made to intubate the patient. Intubation was greatly hindered by the huge tonsils and the presence of fluid in the pharynx. While this was being completed the patient was observed to go into cardiac arrest. The surgeon asked for a scalpel, which was promptly produced, albeit from another room. Thoracotomy followed by cardiac massage was successful in quickly restarting the heart. Meanwhile the patient was ventilated with oxygen through the endotracheal tube. In due course the chest was closed in the normal manner.

Treatment. This patient was not in arrest long, perhaps little over a minute before massage was begun, but she suffered severe hypoxia for several minutes prior to that; however, an EEG taken within 15 minutes showed a waking pattern. It was therefore felt that there was little to worry about from a neurological point of view and this was subsequently shown to be the case. Within 2 hours of her cardiac arrest she was awake and talking. She had a stormy convalescence due to infection of her thoracotomy wound, but as far as could be ascertained she was mentally normal on discharge.

\section{Case 2: Change of Dressings to Third Degree Burns}

A 15-year-old boy weighing $130 \mathrm{lb}$., had a marked toxaemia from extensive burns covering the posterior aspect of his trunk and upper limbs. His haemo-

'Presented at the annual meeting of the Western Divisions, Canadian Anaesthetist:' Society, Victoria, B.C., April 28-30, 1960. 
globin was 69 per cent, and his general coridition was only."fair." His premedication (meperidine $\approx 0 \mathrm{mg}$. and atropine $0.3 \mathrm{mg}$. given $45 \mathrm{minutes}$ before operation) did not sedate him, and he arrived in the operationg room very frightened.

He was anaesthetized on his bed, because of pain, through - a cut-down intravenous catheter in his leg, using thiopentone, $150 \mathrm{mg}$. followed succinylcholine $40 \mathrm{mg}$. and decamethonium $2 \mathrm{mg}$. After ventilation with oxygen an attempt was made to spray his trachea with lidocaine, but this was found to be impossible owing to the awkward angle (on a ward bed), and was immediately abandoned. He was then without further ventilation intubated without difficulty. His colour was good until immediately, on intubation, he lost all colour and pulse. Cardiac arrest was-apparent and the surgical resident immediately opened the chest and massaged the heart, which recommenced a normal rhythm very rapidly. Duration of arrest was again of the order of 1 minute.

This case was difficult to explain at the time, but it would appear to be very similar to a case reported by Hueston Villiere and Flemming of Melbourne, Australia. ${ }^{1}$ They also quote a similar case reported by Finer and Nylèn of Sweden. A similar but fatal case occurred at another local hospital, and it might be that reflexes in these gasses are unduly sensitive to intubation.

Treatment. This patient's general condition was treated with, 1,000 c.c. of blood in the operating room and serum albumen 50 c.c. prophylactically for cerebral oedema. Atropine and methedrine were given intravenously at the time of massage. He was irrational for 6 hours and then responded. In the evening his temperature was $102^{\circ}$ and he was actively cooled with fans and ice packs. On the following day he seemed mentally satisfactory, apart from being a little disorientated as to time. Two days later he was entirely normal.

These two patients were only in arrest for approximately 1 minute, but the second, owing perhaps to his poorer general condition with toxaemia and anaemia, showed some signs of cerebral damage Both these patients had their chests opened, and this is essential if there is to be hope of success.

\section{Case 8}

Preoperative condition. A 75-year-old man was suffering from geute cholecystitis complicated by known arteriosclerotic heart disease a complete heart block, the apex rate was 40 per minute.

The premedication was meperidine $50 \mathrm{mg}$. and atropind $0.6 \mathrm{mg}$. given one hour before operation. Induction was with thiopentone $0.25 \mathrm{gm}$. followed by succinylcholine $40 \mathrm{mg}$. for intubation. Ether, nitrous oxide, and oxygển were used for maintenance. During exploration of the gall bladder bed, 34 minutes after the commencement of 'the anaesthetic, cardiac grrest occurred. Massage was attempted through the abdomen in this case, for obvious reasons, but quickly abandoned and a separate incision make in the thorax. The patient. responded fairly rapidly cardiac massage, ecommencing his normal slow rhythm. Total time of his period of arrest wals 2 'minutes. He had no postoperative troubles referrable to his arrest, despite his shaky cardiovascular system, and toxaemia from his cholecystitis. 
Case 4

A 20-year-old woman had an open heart operation. In the immediate postoperative period she developed a cardiac tamponade and while being prepared for a thoracotomy had cardiac arrest. Cardiac massage was undertaken rapidly with a good result, and she regained consciousness on the operating room table where she could see the clock and exclaimed about the time. She presumably had amnesia for the period intervening between the two operations.

\section{Case 5}

After an open heart operation on a male patient cardiac arrest occurred in the recovery room owing to irritable conduction tissue, conveniently before the eyes of the surgeon. Arrest occurred again in the operating room while the bleeding points were being tied off. On this second occasion, the heart would not restart until after a rapid blood transfusion had been given, despite adequate massage as demonstrated in the electroencephalogram tracing shown in the accompanying figure.

1)

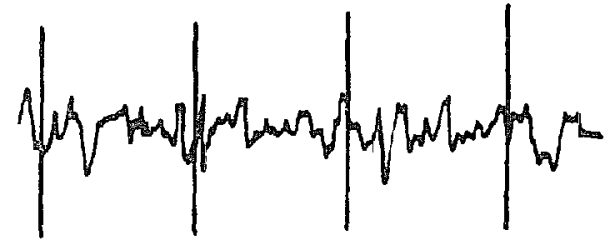

E.E.G. during closure of tharacaforny following orrest on the word.

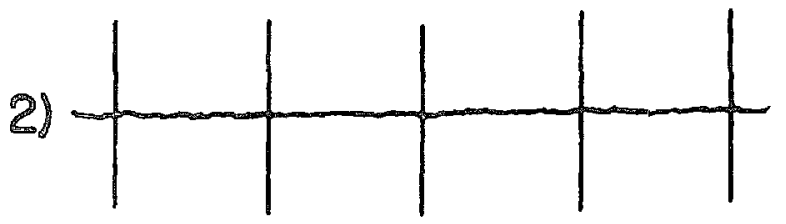

2nd Condice arrest - No massage.<smiles>CCCCC(C)(C)CC(C)CC(C)CC(C)CCC(C)C</smiles>

Still in arrest-effective massoge.

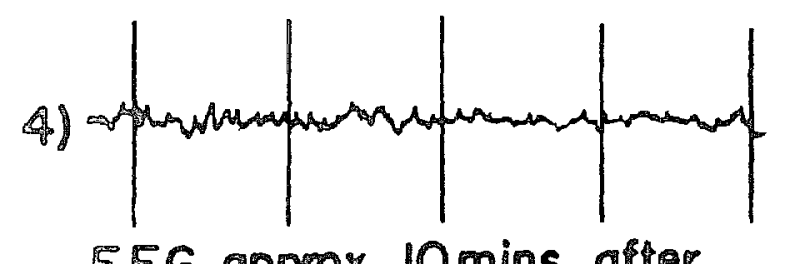

EEG. approx. 10 mins. offer restoration of heart beat.

FIGURE 1. An EEG of case 5.

The electroenceph The EEG was also satisfactory only 10 minutes after restoration of normal rhythm. It was therefore predicted that the neurological outcome would be satisfactory-which indeed it was. 
Case 6

A child had a cardiac arrest on the table, and effective massage was rapidly performed. He regained consciousness on leaving the operating room, and was calling loudly for his mother within seconds.

\section{Case 7}

A male patient was being cooled preparatory to craniotomy under hypo: thermia. On being lifted from the ice bath he developed ventricular filbrillation which required 20 minutes of massage before regular rhythm could be regained. He appeared to have suffered no ill effects from this episode. Undoubtedly the cooling helped here to give some protection.

\section{Case 8}

Cardiac arrest occurred in a 6-year-old child on introduction of an oesóphageal temperature probe. Normal rhythm was established within 1 minute, and convalescence was uneventful from the neurological point of view.

In these eight cases cerebral circulation was interrupted for a brief period mly, and from the neurological point of view gave little cause for concern. In each of these cases the cause of arrest was reversible, being reflex, conduction interference, bleeding, or hypoxia.

What then about the longer cases of arrest? Occasjonally one "gets away" with a longer period of time than three or four minutes, but usually this is not the case. Corday Eliot and Cole Seymour, ${ }^{2}$ in analysing the results of over 100 cases of cardiac arrest found only 2 patients out of 30 who had survived when treat: ment had been delayed for over 4 minutes, and both of these survivors had permanent brain damage. In contrast, in 78 cases where treatment was started within the 4-minute period, 33 made a complete recovery, while those that did not had a major complicating factor present, such as diminished pulmonary function or hypovolaemia. Despite this, it is certainly well worth while to treat the prolonged arrest aggressively, as an unexpectedly good result sometimes occurs, especially in children. The following case is an example of such a result.

\section{Case 9: Intended Operation-Tonsillectomy and Adenoidectomy}

The patient, a 5-year-old boy, was given premedication of meperidine 50 mg. and atropine $0.3 \mathrm{mg}$. 45 minutes preoperatively; induction of thiopent one $150 \mathrm{mg}$., succinylcholine $\mathrm{Cl} .40^{\circ} \mathrm{mg}$., intubated; and maintenance of et her, nitrous oxide, and oxygen. The arrest occurred about 10 minutes after induc tion and about 5 minutes after the commencement of the ether. It wás onty discovered when the anaesthetist noticed the patient's colour.

The duration of arrest was unknown but guessed at beifig at least 3-4 minutes. Following cardiac massage and return of spontaneous rhythm his EEG was flat for 2 hours. The patient was given 50 c.c. of serth albumen intravenously and his temperature was kept in the lower normal range with chlorpromazine and sedation, ice, and fans. On the second and third day his decerebrate rigidity eased and he became semi-conscious. On the fouth day he spoke and then 
made a fairly rapid recovery. At the end of the first month he could walk fairly well, and by two months he appeared to be normal in every respect. This boy is now in his third year at school and he has not failed a grade. His school report cards show high grades and he plays games and sports with the other boys quite normally. His parents are quite happy with his progress.

The recuperative powers of children from this sort of disaster would appear to be quite remarkable. This is also shown by the following much more severe case.

\section{Case 10}

An infant, aged 6 months, was operated on for a patent duetus under ether anaesthesia. During the entire procedure the child was cyanosed owing to chronic infection and bronchospasm. At the end of the procedure the left lung was collapsed and uninflatable. Cardiac arrest was treated by immediate massage, the thorax being still open. The infant required bronchoscopy and forceful re-inflation of the lung. Spontaneous rhythm did not return for 8 minutes. Oxygenation was inadequate throughout bedause of bronchospasm.

Postoperatively the EEG was flat and there was no response to stimuli: convulsions were prominent and controlled with phenobarbitone. For two weeks the patient did not move all her limbs and her plantar responses did not return to normal. The head was still held hyperextended. At four weeks she was not appreciably changed; she turned towards noise but appeared quite definitely blind. She was seen one month ago and appears to be a bright child of two years of age and the neurologist states that she would appear to be normal. She has however a strabismus which may or may not have some connection with the arrest.

These last two cases demonstrate the more severe problems presented by prolonged cardiac arrest. What then of the treatment? In our experience if the patient, is well ventilated and adequately trimsfused, rapid restoration of spontaneous rhythm occurs. As Gain ${ }^{3}$ and others have pointed out, the electro. encephalogram is extremely valuable as a monitor of the state of the cerebral circulation, particularly in cardiac and certain other poor risk cases. It is also useful in prognosis following cardiac arrest, as shown by Bellville and Howland."

As a rough guide it may be stated that the prognosis is good if the fast activity in the EEG is restored within 1 hour. If it continues flat for over 4 hours there is strong evidence of irreversible cortical damage.

\section{Conclusion}

Our experience confirms that of many others that, provided everybody is well rehearsed, a good result can often be obtained provided cardiac arrest is quickly spotted and treated. However if the prearrest period is complicated by respiratory, cardiovascular, or other factors, such as toxaemia, the final outcome may be seriously jeopardized. The remarkable recuperative powers of children, as shown in the last two cases, should be born in mind when treating these serious problems. 


\section{SUMMARY}

Ten cases of cardiac arrest who recovered from the event are presented. The last two cases show the remarkable powers of recuperation possessed by children in recovering from what appeared at the time to have been a very. severe degree of brain damage.

\section{REFERENCES}

1. Fleming, W. B., Hueston, J. T.; Stubbe, J. L.; \& Villiers, J. D. Tuo Episodés of Cardiac Arrest. Brit. Med. J. $i$ : 157 (1960).

2. Cole, S. L, \& Corday, E. The Internist and Cardiac Arrest. A.M.A Arch. Int. Med. 104: 37 (1959).

3. GaIN, E. A. The Practical Value of the Electroencephalogram during Anaesthesia. Canad. Anaesth. Soc. J. 6: 227 (1959).

4. Belfintle, J. W., \& Howland, W. S. Prognosis after Severe Hypoxia in Man. Anésthesiology 18: 389 (1957). 